\title{
Rapid Prototyping of the Injection Device Piston Used for Fertigation Using 3D Printing Technology
}

\author{
GHEORGHE SOVĂIALĂ ${ }^{1}$, ALEXANDRU-POLIFRON CHIRIT $\check{\check{A}}^{1 *}$, SAVA ANGHEL $^{\mathbf{1}}$, DRAGOȘ MANEA ${ }^{2}$ \\ ${ }^{1}$ Hydraulics and Pneumatics Research Institute INOE 2000-IHP, 14 Cuțitul de Argint Str., 040558, Bucharest, Romania \\ ${ }^{2}$ National Institute of Research-Development for Machines and Installations Designed to Agriculture and Food Industry - INMA, \\ 6 Ion Ionescu de la Brad Blvd., Bucharest, Romania
}

The article presents the process by which, with the help of $3 D$ printing technology, the piston of the differential injection device was produced using ABS material. It was made with fused filament fabrication $(F F F)$ technology, and the smoothing process was used to improve the surface quality. The piston is part of a complex equipment for underground fertilization of agricultural crops.

Keywords:3D printing, acrylonitrile butadiene styrene (ABS), thermoplastic polymer, vapor smoothing.

3D printing (3DP), specifically fused filament fabrication (FFF), is one of the most accessible and widespread rapid prototyping technologies [1]. Recent advances in additive manufacturing (AM), a construction technique where a three-dimensional object is created through the build-up of thin layers of a thermoplastic material, have resulted in the commercialization and popularization of what is commonly known as 3DP. Objects for 3D printing are stored in digital files for modification using 3D modeling software, and are easily copied and transferred via the Internet. Rapid prototyping procedures make it possible to produce relatively complicated parts based on computer 3D geometries. Most of the rapid prototyping processes can create parts from a variety of common and special materials [2-5].

The modernization of the agricultural works has been marked by several important steps, among which we can mention:

- Land leveling by an optical reference plane, generated by a rotating laser emitter [6], made with navvy machines equipped with modular hydraulic drive and laser control systems. This type of land works allows a more efficient use of water coming from irrigation or rainfall for plants grown on agricultural land and lower soil compaction, due to a lower number of passes of the leveling machines on the ground.

- Fertigation, made by directly injecting the fertilizer into the irrigation pipeline, with the help of special pumping equipment.

Compared to the situation where irrigation and fertilization are carried out as distinct sequences in agricultural technological processes [7-10], fertirigation presents a series of advantages arising from the following considerations [11-13]:

- It replaces the classic system of chemical fertilizer administration, which implies the existence of a system of complex machines, significant energy and labor force consumption, coefficient of uniformity of the reduced distribution, removal of plants from the wheels of the machines involved in the technological process;

- It facilitates the rapid access of the fertilizing substances to the root system of the plants, at the opportune moment, their superior use; from the studies carried out it was found that in the classic system of fertilization, in the normal years from the point of view of precipitation the plants capitalize approx. $65 \%$ of the applied nutrients in the form of fertilizers, while in the drought years they can only use 40\%;

- It significantly reduces the losses of the active substance by evaporation, gravitational leakage or percolation under the root layer of plants, under the influence of unfavorable climatic factors (high temperatures associated with strong winds, heavy rainfall), a process commonly encountered in the case of chemical fertilizers that are stationary for a prolonged period on the surface of the soil;

- It reduces the degree of injury of the plants, caused by the direct contact of the fertilizers with the upper part of the plants;

- It allows very precise dosing of the components of the primary solution (which together with the irrigation water forms the fertilizing solution), depending on the nutritional requirements of the plants, determined by chemical soil analysis;

- It facilitates the administration of chemical fertilizers in the final stages of growth and development of plants, when access to fertilization equipment in culture is practically impossible; failure to apply fertilizer norms for these vegetation phases usually leads to lower agricultural production and seed quality.

*email: chirita.ihp@fluidas.ro / 0769.404 .303 
The equipment of which the piston is part will be designed for working in aggregate with fixed and mobile drip irrigation installations and underground irrigation. The injection device, which constitutes the main component of the system, is of the type hydraulic amplifier with differential piston and mechanical-hydraulic control, capable of operating in the specific pressure range for drip and underground irrigation installations, for a wide range of primary solution concentrations. The mixture between the primary solution and the irrigation water used as a motor fluid (which constitutes the fertilizing solution) will be made right in the body of the injection device, completely eliminating the losses of irrigation water outside the system. The irrigation equipment can be located at any point of the irrigation plot, the injection device using as working fluid the irrigation water from the system. The differential motor piston dosing device and the piston injection pump have major advantages compared to the volumetric dosing devices with membranes used in agriculture: the volume of the injected fertilizer solution is strictly proportional to the volume of water entering the unit, regardless of the variations of flow or pressure that may occur in the main pipe; the water used as a motor fluid mixes with the primary solution inside the device, forming the fertilizing solution; this is introduced in the pipeline of the localized irrigation system and diluted to an optimum concentration, which eliminates the risk of crop over-fertilization, thus contributing to the protection of plants, consumer health and the environment.

Structure and operation of the device: the mechanical-hydraulic device for actuating a motor piston (1) (figure 1) from the structure of an injection device type DOZATRON characterized by the fact that it is equipped with two piloted hydraulic valves (2) and (6), connected through two hoses (x-x) and (y-y) to two nozzles (7), which are successively sealed by a rubber surface of a tilting device (8) that tilts against an axis (9) depending on the position of a probe (11) which by means of an arm articulated to the shaft (9) forces a spring and the its guide (10) to press alternately, (see the two details in figure 1) on the rubber tipping device and to press the rubber surface on the holes of the nozzles producing the alternative filling of them and therefore piloting the two valves, which by closing and opening them alternatively make successive connections between chambers A and B as well as B and C, and consequently, under the action of the water from the installation, produce alternate rectilinear movement of the drive piston.
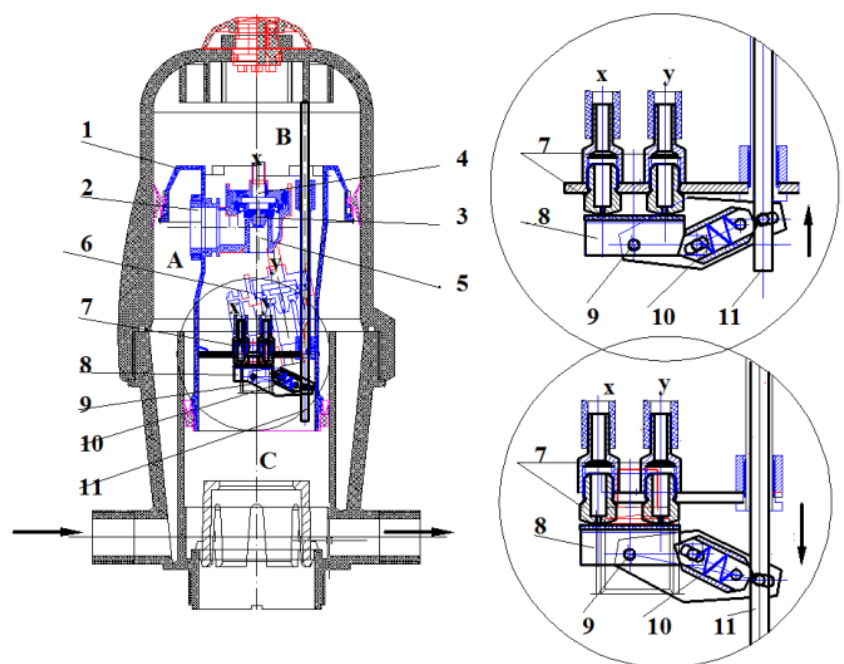

Fig. 1. The mechanical-hydraulic device for actuating a motor piston

\section{Experimental part}

Materials and methods

This section presents the 3D printing process of the piston and the process of improving surface quality. Figure 2 shows the 3D model made in the SolidWorks modeling software, as well as a section of it.

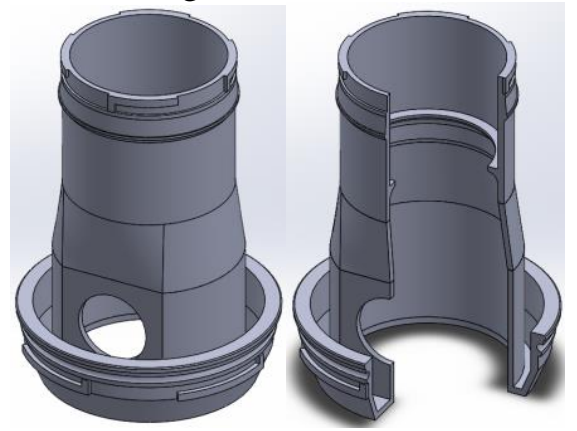

Fig. 2. 3D CAD models from the SolidWorks software 


\section{The prototyping process of functional model}

Printing was done on the BCN3D SIGMA R19 Printer (FFF) with the following facilities:

- $\quad$ Architecture: Independent Dual Extruder (IDEX);

- $\quad$ Printing volume: $210 \mathrm{~mm}$ x $297 \mathrm{~mm}$ x $210 \mathrm{~mm}$;

- Heated bed maximum temperature: $100{ }^{\circ} \mathrm{C}$;

- Positioning resolution (X/Y/Z): $1.25 \mu \mathrm{m} / 1.25 \mu \mathrm{m} / 1 \mu \mathrm{m}$;

- Firmware: BCN3D Sigma - Marlin;

- Extruder system Extruder Bondtech TM high-tech dual drive gears; Hotends: Optimized and manufactured by e3D TM;

- File preparation software: BCN3D Cura.

The piston body was made of ABS filament and the support structure was intended to support the layers with an angle greater than $45^{\circ}$.

Parameters of the 3D printing process: the filament diameter was $2.85 \mathrm{~mm}, 0.4 \mathrm{~mm}$ hotend diameter, $0.2 \mathrm{~mm}$ layer height, $99 \%$ infill density, $250{ }^{\circ} \mathrm{C}$ printing temperature, $95{ }^{\circ} \mathrm{C}$ build plate temperature and a conservative print speed of $55 \mathrm{~mm} / \mathrm{s}$.

The 3D model was converted to STL format and was imported into the Cura slicer (Figure 3) where the printing parameters were set.

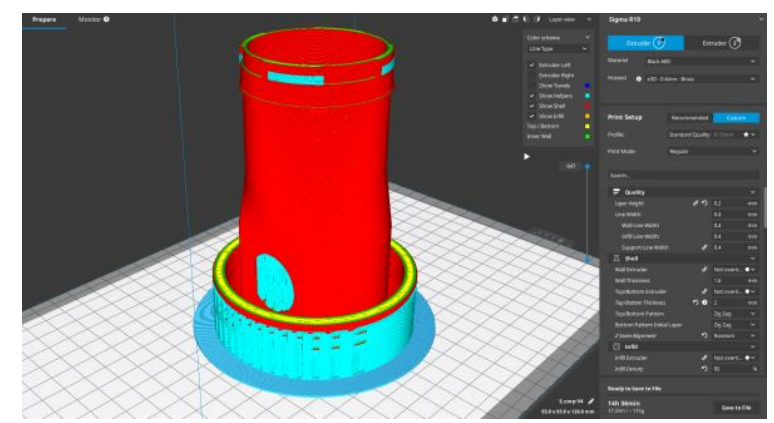

Fig. 3. The 3D model of the piston from the Cura slicer

The piston resulted at the end of printing can be seen in figure 4, as well as the fact that a closed enclosure was used during printing to prevent the deformation of the part and the delamination of the layers.

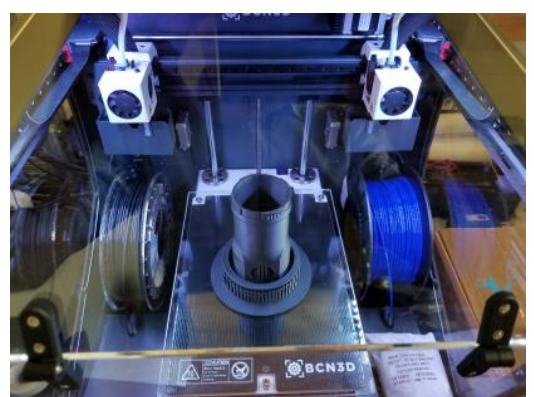

Fig. 4. 3D printer and piston body at the end of the printing process

Following the fabrication process the part was cleaned of the support material and the dimensional accuracy was checked as well as the sealing fit (figure 5).

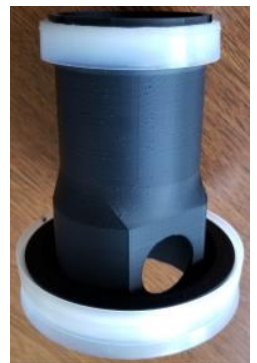

Fig. 5. Piston body with seals fitted 
Due to the fact that the fertigation pump operates at a maximum pressure of 6 bar and for a smoother flow of the liquid through the pump body, the piston has been applied the "vapor smoothing" process (figure 6). This process consists in the superficial melting of the surface of the ABS part with the help of an acetone vapor bath. The piston was placed in a tightly sealed vessel that has a sieve high up against the bottom of the vessel on which the piece sits. On the bottom of the vessel there is acetone and a piece of metal embedded in the glass that is driven by a device that heats the vessel and at the same time rotates the metal piece. Stirring the acetone as well as increasing the temperature increases the rate of acetone evaporation and finally the duration of the entire process.

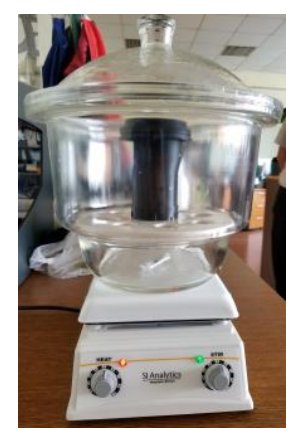

Fig. 6. Vapor smoothing process installation

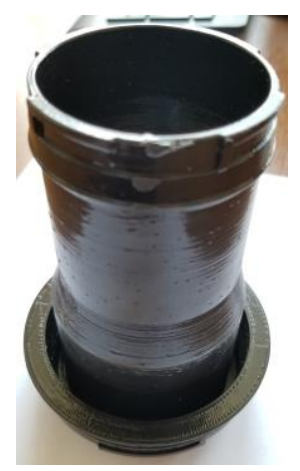

Fig. 7. Surface quality after vapor smoothing process

After about 15 minutes, the piece was removed from the vessel and left for the molten acetone surface to harden. The final quality of the surface can be seen in figure 7 .

\section{Experimentation of the functional model}

The experimental part had the role of confirming that the piston manufactured by 3D printing resists and works at a nominal pressure of the 3.5 bar system and that the mechanism designed at IHP increases the pressure on the device's discharge.

The experimentation was performed on a stand dedicated to agricultural irrigation, in the Water Hydraulics Laboratory, the same where the specialists of IHP have conducted previous tests [14]. The pumping group is shown in figure 8 , and it consists of a group of two electro-pumps and a pressure accumulator.

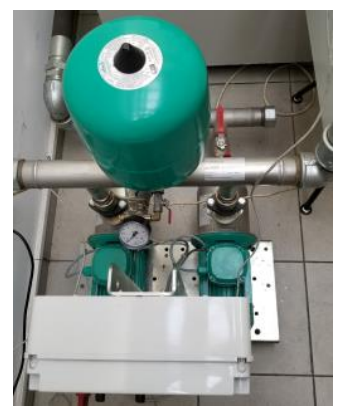

Fig. 8. The irrigation stand pumping group

Figure 9 shows the control panel, which has the possibility to adjust the pumping pressure.

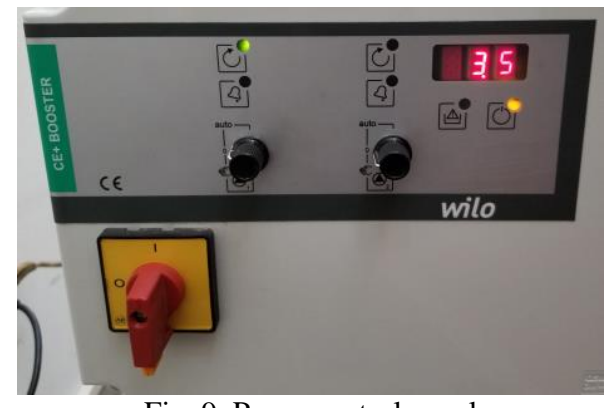

Fig. 9. Pump control panel 
Figure 10 shows the piston with the valves mounted and the control mechanism of the valves. The piston is inserted in a temporary pump body, for conducting experiments. Two pressure transducers are mounted on the pump suction (left) and its discharge (right). The pressure on the pump discharge is made with the help of a tap.

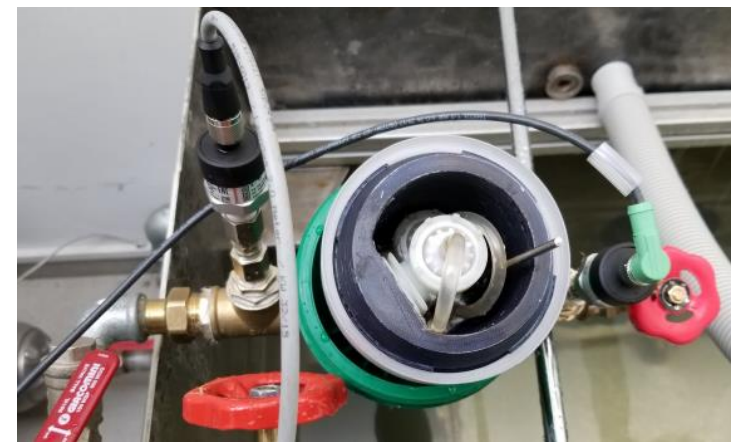

Fig. 10. The piston with the valves mounted and the control mechanism

The pressure gauge shown in figure 11 indicates the pressure on the pump inlet which is made using the red rosette valve in the figure.

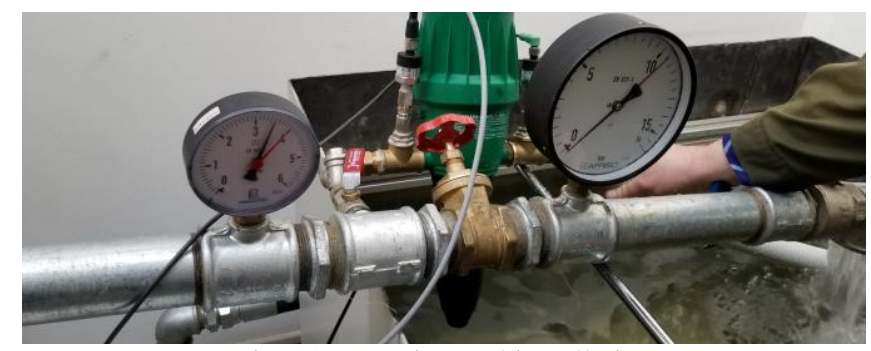

Fig. 11. Experimental installation

The analog pressure variation measured by the two pressure transducers was converted to digital values using the PLC shown in figure 12, which transmits data to a PC via the Internet interface.

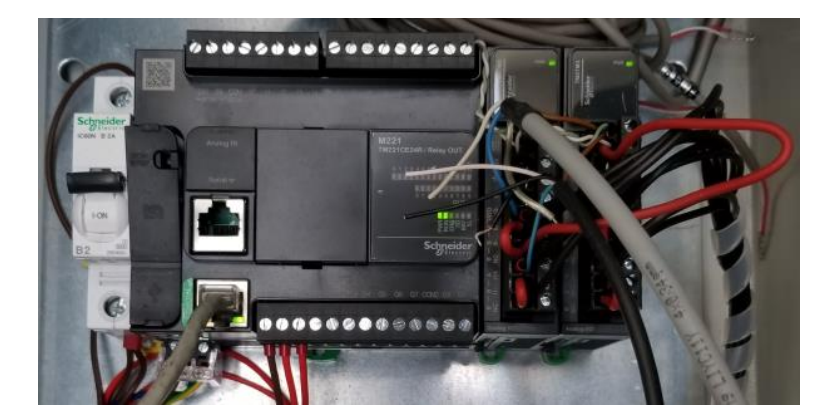

Fig. 12. The PLC with which the experimental data was acquired

\section{Results and discussions}

Following the manufacturing process with the help of 3D printing, the piston body of the fertigation pump was made and it is shown in figure 13.

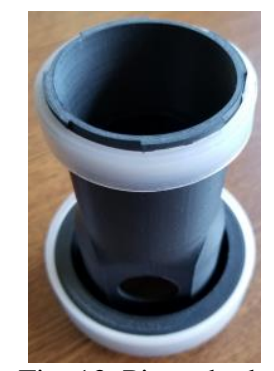

Fig. 13. Piston body

Following the experiments on the irrigation stand the graph of pressures in figure 14 resulted. 


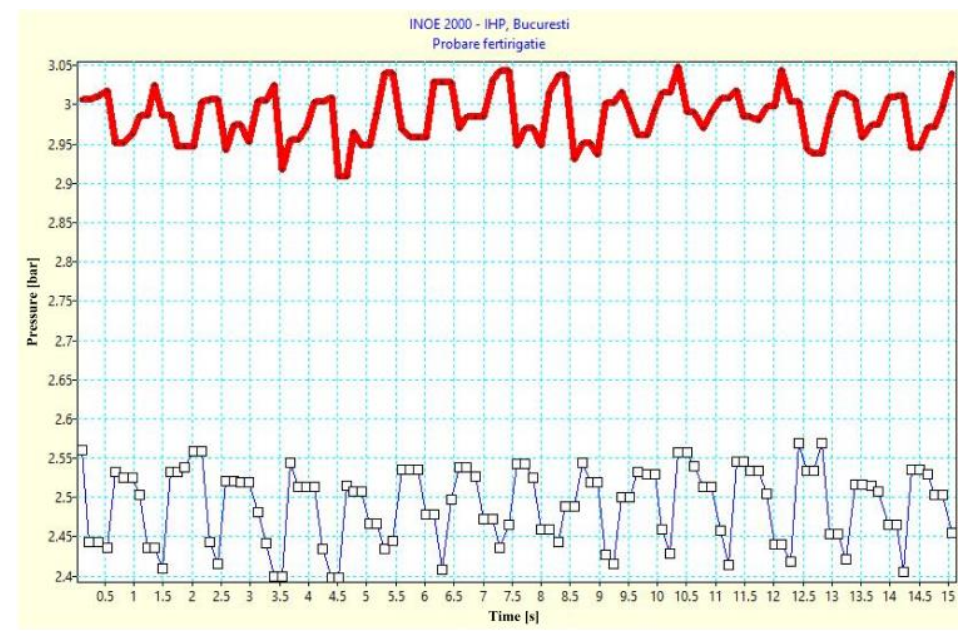

Fig. 14. Pressure graph from the fertigation pump

The graph in figure 14 presents the variation in time of pressure on the intake of the fertigation pump with blue (thin) line and on the discharge with red (thick) line.

One aspect that needs to be clarified is the difference between the pressure value measured with the pressure gauge on the pump suction and the value measured by the pressure transducer on the same branch. The difference is about 1 bar and is due to pressure drops on the route.

\section{Conclusions}

With the help of 3D printing technology, the piston body of the irrigation pump could be manufactured, according to the execution drawings, very quickly and at low costs. Due to the additive nature of this technology, complex parts that could not be made with other classic manufacturing processes can be made.

Following the experiment on the irrigation stand it was found that the piston body of the pump has withstood the nominal pressure of use without cracking and without visible deterioration.

The functional model of differential piston together with the control mechanism of the piloted valves can be considered validated because in the graph of figure 14 a difference of approximately 0.5 bar can be noticed between the inlet pressure and the discharge pressure of the pump.

This paper has been funded by the Romanian Ministry of Research and Innovation under Programme I-Development of national R\&D system, Subprogramme 1.2 - Institutional performance - Projects financing excellence in R\&D+I, Financial Agreement no. 19PFE/17.10.2018, while scientific results are obtained under Project INNOVATIVE TECHNOLOGIES FOR IRRIGATION OF AGRICULTURAL CROPS IN ARID, SEMI-ARID AND DRY SUB-HUMID CLIMATE, project number PN-III-P1-1.2-PCCDI-2017-0254, Contract no. 27PCCDI / 2018, within PNCDI III.

\section{References}

1.BORDONI, M., BOSCHETTO, A., Rapid Prototyping J., 18, no. 4, 2012, p. 308

2.ADAM, G., ZIMMER, D., Rapid Prototyping J., 21, no. 6, 2015, p. 662

3.NOVAKOVA-MARCINCINOVA, L., KURIC, I., Manuf. and Ind. Eng., 11, no. 1, 2012, p. 24

4.NEDELCU, D., COJOCARU, V., MICU, L.M., D FLOREA, F., MIHAI HLUSCU, M., Mat. Plast., 56, no.2, 2019, pp. 454-459

5.ZAPCIU, A., AMZA, C.G., RONTESCU, C., TASCA, G., Mat. Plast., 55, no. 4, 2018, p. 517-520

6.POPESCU, T.C., DRUMEA, A., DUȚU, I., Numerical simulation and experimental identification of the laser controlled modular system purposefully created for equipping the terrace leveling installations, 31st International Spring Seminar on Electronics Technology (ISSE 2008), Budapest, Hungary, 7-11 May 2008, pp. 334-339

7.VLASA, A., BIRIS, C., LAZAR, L., BUD, A., BUD, E., CERNUSCA MITARIU, I.S., PACURAR, M., Mat. Plast., 54, no. 1, 2017, p. 122

8.BUDEA, S., CHIUJDEA, C.M., Mat. Plast., 52, no. 1, 2015, p. 65

9.POPESCU, M., MITELEA, I., BORDEASU, I., Mat. Plast., 47, no. 4, 2010, p. 446

10.BLIDARU, V., PRICOP, Gh., WEHRY, A., Irigatii si drenaje, Editura Didactica si Pedagogica, Bucuresti, 1981, p. 34

11.GHEORGHE, G., MANEA, D., MATEESCU, M., POPA, R., POPA, V., ȘOVĂIALĂ, Gh., CAD-CAE model for the structural analysis of a drip tape injection equipment for subsurface irrigation, 2018 International Conference on Hydraulics and Pneumatics - HERVEX, Băile Govora, Romania, 7-9 November 2018, pp. 211-217

12.ŞOVĂIALĂ, Gh., MATACHE, G., POPESCU, A.I., POPESCU, A.-M.C., DRĂGHICI, I., MANEA, D., SEPTAR, L., Considerations on irrigation and fertilization of agricultural crops on sandy soils in arid, semiarid and dry sub-humid climate, 2018 International Conference on Hydraulics and Pneumatics - HERVEX, Băile Govora, Romania, 7-9 November 2018, pp. 231-243

13.ŞOVĂIALĂ, Gh., ANGHEL, S., MATACHE, G., POPESCU, A.I., MANEA, D., Contributions to the development of the field of fertigation equipment, ISB-INMA TEH' 2018 International Symposium, Bucharest, Romania, 1 - 3 November 2018, pp. 593-602

14.POPESCU, T.C., DUMITRESCU, C., BORDEASU, I., Mat. Plast., 53, no. 1, 2016, p. 174 
